\title{
Model competence, depression, and the illusion of control
}

\author{
STEVEN P. DYKSTRA and STEPHEN J. DOLLINGER \\ Southern Illinois University, Carbondale, Illinois
}

\begin{abstract}
The illusion of control has been demonstrated repeatedly in studies involving the manipulation of three of the four factors identified as important by Langer (1975): choice, familiarity, and involvement. The present study was designed to replicate and extend research on one other factor: competition or social comparison. Mildly depressed and nondepressed subjects watched a competent or incompetent model perform a novel gambling game. After learning of the model's ostensible performance level (a score equal to the chance probability), subjects predicted their own level of immediate performance and what it would be if they were given 1 week to practice the game. Subjects witnessing the incompetent model gave higher performance predictions than those witnessing the competent model, thus replicating and extending Langer's "dapper" versus "schnook" study on competition. As a group, subjects predicted better performance after practice rather than immediately, thus providing further support for the familiarity factor. Contrary to findings in past research, mildly depressed subjects showed an illusion of control and did so to a greater extent than did nondepressed subjects.
\end{abstract}

Langer (1975) defined the illusion of control as an expected probability of personal success that is higher than objective probabilities would warrant. In providing the initial demonstrations of the phenomenon, she identified four factors that ought to promote this illusion: stimulus or response familiarity, choice, involvement, and competition. A number of studies have been done to demonstrate the existence of the illusion of control, suggesting its relevance to such real-world behaviors as gambling, mania, and belief in extrasensory perception (Ayeroff \& Abelson, 1976; Benassi, Sweeney, \& Drevno, 1979; Langer \& Roth, 1975; Stern \& Berrenberg, 1979; Tennen \& Sharp, 1983). Most of these studies have elicited the illusion through (at least implicit) manipulation of the factors of choice, familiarity, and involvement. However, Langer (1975, Study 1) did show that people had a greater illusion of control when playing against a clumsy, inept confederate (termed the "schnook") than against a confident, "dapper" one. The first purpose of the present study was to conceptually replicate and extend Langer's study showing a greater illusion of control when one's competition (or more precisely, social comparison target) appears less competent. ${ }^{1}$

A second purpose of the present study was to explore this competition factor in conjunction with the variable of subject depression. Golin, Terrell, and their colleagues have suggested that, due to a general sense of personal incompetence, depressed subjects tend not to exhibit the illusion of control (Golin, Terrell, \& Johnson, 1977; Go-

Requests for reprints should be addressed to Steven P. Dykstra, Sinai Samaritan Medical Center, 2200 W. Kilbourn, Milwaukee, WI 53233. lin, Terrell, Weitz, \& Drost, 1979). It seems likely that this will be especially true when depressed subjects implicitly compare themselves with a competent model or competitor. However, when comparing themselves with an incompetent model, they might be more likely to show an illusion of control. This possibility makes sense, given the effects of socially desirable and undesirable models on observers' self-esteem (Morse \& Gergen, 1970). Thus, it seems important to study the competition and depression variables in combination.

A third purpose of the present study was to test an extrapolation from Langer's familiarity factor. Specifically, we wished to assess whether subjects' subjective success probabilities would increase when they imagined the possibility of practicing the game for one week. Such a finding would be consistent with Langer's description of the stimulus familiarity factor in the illusion of control. This effect, if found, would also be consistent with several studies that have shown greater beliefs in one's ESP when one is given an opportunity to "warm up" or practice prior to the ESP test (Ayeroff \& Abelson, 1976; Benassi et al., 1979). In sum, in the present study, we tested college students' illusions of control at a novel gambling task after they had been introduced to the task by a competent or incompetent model. The subjects were either mildly depressed or nondepressed. Their success estimates were obtained for immediate performance and for performance after 1 week of practice. (These will be referred to as the immediate and the after-practice expectancies.) It was predicted that the illusion would be (1) greater with an incompetent than with a competent model, (2) greater among nondepressed than among depressed subjects, and (3) more clearly evident in subjects' after-practice expectancies than in their immediate expectancies. 


\section{METHOD}

\section{Subjects}

Introductory psychology students ( 38 male, 38 female) were solicited for a study on "the ability to predict personal performance." They earned extra course credit by participating. To determine level of depression, a median split was performed on the distribution of scores on the Beck Depression Inventory (BDI), using a median of 5 in this sample. The subjects saw models of their own sex. The models were a male and female graduate student who dressed and acted both the competent and incompetent parts.

\section{Task}

The task involved a novel gambling activity that required a standard deck of playing cards (from which kings and aces were removed) and a pair of dice. The game had two steps, which together made for a high level of involvement. In the first step, the player was to cut the deck and roll the dice. Based on the resulting configuration, there were two ways to win: by obtaining either a match-a card showing a 5 and the dice summing to 5 (with the point values of jack and queen equalling 11 and 12 , respectively) - or an automatic win (a 2 or a queen on the card cut from the deck). If the player did not win in the first step, he or she had an opportunity to win in the second step by choosing one of the two dice and attempting again to make a match. Thus, the game included much active involvement and choice, with presumably familiar materials. With a probability of .364 on each trial, the most likely score, given 30 trials of the game, would be 11 wins. This score, then, served as a benchmark for comparison with the model (who ostensibly won 11 times out of 30) and with chance performance.

\section{Procedure}

The subjects were scheduled to participate in groups of $3 .^{2}$ Upon arrival at the research office, they completed the BDI and a personal data sheet asking about current academic, leisure, and social experiences. Then they were seated at a long table with a pair of dice and deck of cards at each position, with seats facing a video monitor. The experimenter explained that the research concerned the ability to predict one's own performance. The alleged purpose was to discover the characteristics of those whose predictions were most accurate, this being the justification for giving the BDI and requesting personal data. The experimenter then started the videotape, which showed a college student being interviewed (using the same personal data questions), being instructed in the gambling task, and then playing several trials of the task. Each group of 3 was randomly assigned to view the competent or incompetent model tape.

Competent model. Like Langer's “dapper" competitor, the competent model was neatly dressed and well groomed. When asked about academic and social activities, this model replied with answers that indicated confidence, definite plans and goals, and an active involvement in life. For example, when asked about living arrangements, the model assertively replied, "I have my own place." When asked about favorite leisure activities, the model said, "parties, sports, lots of things." The model was also portrayed as having decided on majoring in chemistry and as having been romantically involved with one person "for quite some time."

Incompetent model. Incompetent models were dressed in moderately worn jeans and were groomed in a way that suggested a lack of concern for the finer details. This model's answers indicated a lack of selfconfidence, an indecisiveness, and a passive involvement in life. For example, when asked about living arrangements, the model hesitantly replied, "I live alone ... I don't have any roommates." When asked about leisure activities, the model said, "television," and then seemed unable to think of any other activities. This model was undecided about a major and merely shrugged when asked about having any romantic affiliation. After the interview, the models were introduced to the game and played two trials. The models were depicted as having different degrees of confidence in their playing of the game as well. For example, early during the instructions, the competent model asked if the jack equalled 11 , thereby "beating the experimenter to the punch." The experimenter instructed the incompetent model in this point of the game. Later, the incompetent model was shown being uncertain and request- ing clarification about whether he or she could roll either of the dice at the second step, whereas the competent model confidently selected a die at this point in the script. (Note that the incompetent model never modeled rule-inconsistent behavior.)

\section{Dependent Variables}

So that their subjective success expectancies could be obtained, the subjects were instructed (orally and in writing) as follows: "Keeping the game in mind and considering that the person you just saw on the tape was able to achieve 11 successes in their 30 trials, how many successes do you predict for yourself?" Then they were asked, "If you were able to take the cards and the dice used in the game home for one week and could practice as much as you wanted, how many successes would you then expect on 30 trials?" The subjects were also asked to rate the game in terms of the type of involvement that it required, on a 7-point scale ranging from "entirely luck" (1) through "entirely skill" (7). Finally, a subsample $(n=45)$ of subjects were asked to complete several items as manipulation checks, added after the initiation of the study. These were 7-point scales assessing perceptions of the model's competence, successfulness, likableness, and happiness. The subjects were debriefed after they completed the dependent measures.

\section{RESULTS}

Preliminary tests showed that gender made no difference in the present data set, so analyses collapsed across this factor. Manipulation checks showed that the models were viewed as would be expected. The competent models were rated as significantly more competent, happy, successful, and likable than were the incompetent models (all $t$ tests $>6.0, p<.001$ ).

Because the usual measure in illusion of control research is equivalent to our immediate expectancy, we analyzed it first as a single dependent variable. This analysis consisted of a model competence $\times$ subject depression or $2 \times 2$ between-groups ANOVA. As predicted, the incompetent models yielded greater illusions of control than did the competent models $[F(1,72)=6.0, p<.05]$. Level of depression yielded a marginally significant effect in the direction opposite to that predicted $[F(1,72)=$ $3.9, p<.06]$. Figure 1 graphically depicts these effects.

Because we can view the immediate versus afterpractice questions as two levels of a repeated-measures factor, a second analysis was done, adding time as another factor in a mixed model design. In this ANOVA, time yielded a strong main effect, which was consistent with expectations $[F(1,72)=26.5, p<.001]$. Depression had a significant effect in this analysis, again with depressed subjects showing a greater illusion of control $[F(1,72)=$ $5.8, p<.05]$, and model competence had a marginal effect $[F(1,72)=3.0, p<.10]$.

Figure 1 shows the means for this three-way partition of the data and highlights the means that individually differ from the model's reported performance level and the theoretical parameter of 11 wins. (These tests consisted of the $t$ test for the significance of a single mean, using $p<.01$, two-tailed test.) For the immediate performance estimate, it is evident that only depressed subjects witnessing an incompetent model showed an illusion of control. For the after-practice estimates, the only subjects failing to show an illusion of control were nondepressed individuals who witnessed a competent model. Indeed, 

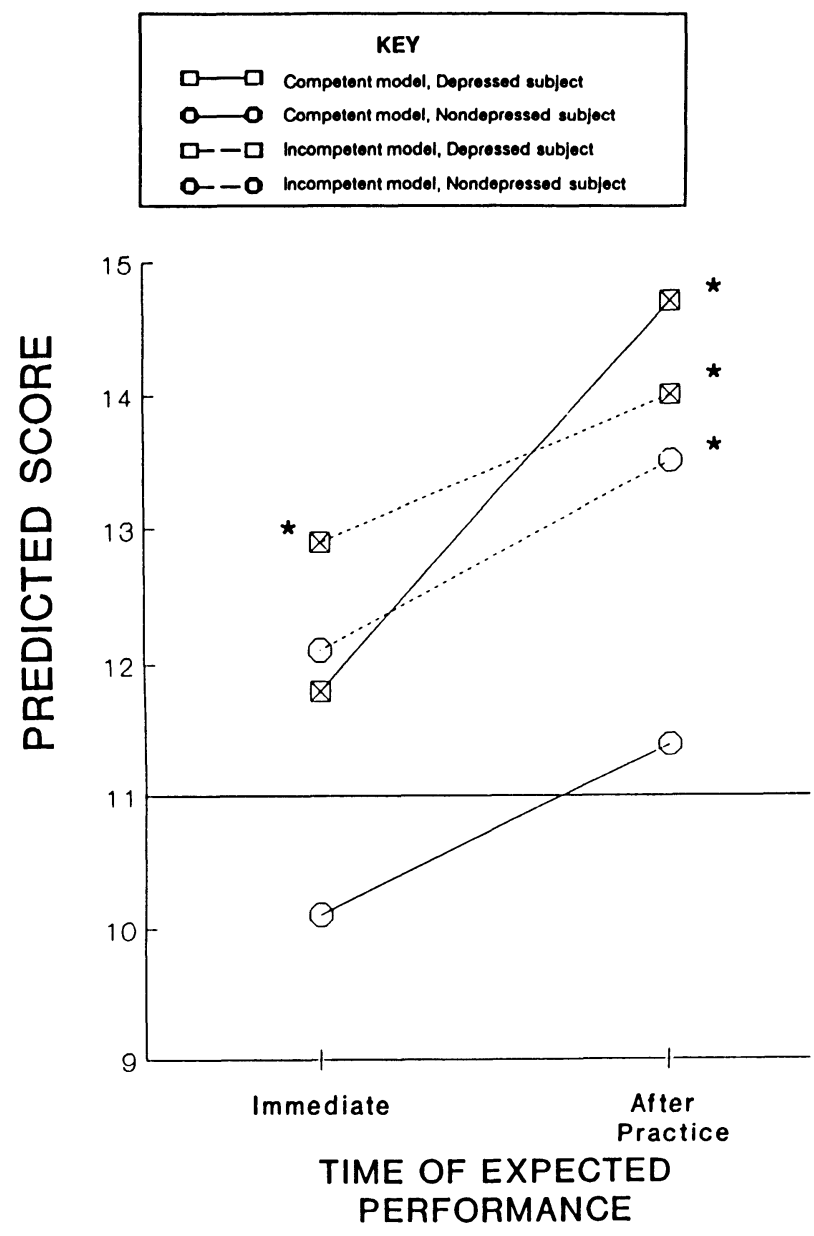

Figure 1. Predicted performance means for all conditions of the experiment. The line at the score of 11 represents the most rational prediction of successes in $\mathbf{3 0}$ trials and the ostensible performance of the model. Asterisks signify that an individual mean differs from 11 ( $p<.01$, two-tailed). Squares are depressed subjects' means; circles are nondepressed subjects' means. Solid lines are for competent models; broken lines are for incompetent models.

these subjects failed to show the illusion for either question; however, the slope of the line connecting these means shows some tendency for increasing expectancy of success with the imagined practice. Perceptions of the task as involving skill rather than luck were analyzed in a $2 \times 2$ ANOVA with model competence and subject depression as the independent variables. Neither factor nor their interaction approached significance. As a group, the subjects perceived the task as primarily involving luck $(M=$ 2.2 on the 1-7 scale).

\section{DISCUSSION}

The results replicate and extend Langer's (1975) work on the role of competition and familiarity in influencing the illusion of control. They extend her findings on competition by showing that direct competition may be unnecessary. The implicit social comparison of oneself with a model who demonstrates a task may be sufficient to raise subjective probabilities of success above what is warranted by the situation. Research on the familiarity factor is extended by the demonstration that, as a group, the present subjects believed that they could improve their performance in the gambling game with a week of practice, even though they viewed the task as primarily luck-determined.

The most surprising finding in the present study was the effect of subjects' preexisting levels of depression. In contrast with past research by Golin and his colleagues, we found that depressed subjects do exhibit an illusion of control and, under some circumstances, a greater illusion than is shown by nondepressed subjects. These findings are not easy to reconcile with past research. It should be noted that our depressed subjects were in fact very mildly depressed, perhaps less depressed than the subjects in other studies in which the BDI was used with college students. ${ }^{3}$ If our depressed subjects were considered to be fairly normal, we would still have difficulty understanding why the "very nondepressed" would show less of an illusion of control. It is possible that our subjects were-and realized themselves to be-transiently depressed. Given that the depression effect emerged more strongly for the afterpractice expectancies, depressed subjects might have felt that they would improve on any task if it were attempted in 1 week. In support of this point, only nondepressed subjects yielded strong correlations between illusory control and perception of the task as involving skill. The skill rating correlated with performance after practice most strongly among nondepressed subjects viewing the incompetent model, the group theoretically most likely to show an illusion of control $(r=.72, p<.001$, $n=20$ ). Furthermore, other correlations between skill rating and performance predictions were marginally significant among nondepressed subjects in both model conditions. Such correlations were near zero for the depressed subjects. It is possible, then, that the nondepressed subjects felt that an "internal" factor (such as ability or effort) might come into play during the week of practice. However, depressed subjects may have thought that improvement would come about with a change in their mood states. Thus, the present results suggest several intriguing questions for further study. Do depressed and nondepressed individuals differ in their underlying beliefs about how they will succeed, given greater time or familiarity with the task? What kinds of skill (or effort) factors do the nondepressed think they can implement to improve their performance? Do perceptions of one's depressed mood state as transitory rather than chronic influence the illusion of control? As these questions are addressed, additional study would also be useful in testing the reliability of the surprising depression effect found here.

\section{REFERENCES}

Ayeroff, F., \& ABelson, R. P. (1976). ESP and ESB: Belief in personal success at mental telepathy. Journal of Personality \& Social Psychology, 134, 240-247.

Benassi, V. A., Sweeney, P. D., \& Drevno, G. E. (1979). Mind over matter: Perceived success at psychokinesis. Journal of Personality \& Social Psychology, 137, 1377-1386.

Golin, S., Terrell, F., \&ohnson, B. (1977). Depression and the illusion of control. Journal of Abnormal Psychology, 186, 440-442.

Golin, S., Terrell, F., Weitz, J., \& Drost, P. L. (1979). The illusion of control among depressed patients. Journal of Abnormal Psychology, 188, 454-457.

LANGer, E. J. (1975). The illusion of control. Journal of Personality \& Social Psychology, 132, 311-328.

LANGER, E. J., \& RoTH, J. (1975). Heads I win, tails it's chance: The illusion of control as a function of the sequence of outcomes in a purely chance task. Journal of Personality \& Social Psychology, 132, 951-955.

MORSE, S., \& GERGEN, K. J. (1970). Social comparison, self-consistency, and the concept of self. Journal of Personality \& Social Psychology, 16, 148-156.

STERN, G. S., \& BERRENBERG, J. L. (1979). Skill-set, success outcome, and mania as determinants of the illusion of control. Journal of Research in Personality, 113, 206-220.

TENnen, H., \& ShARP, J. P. (1983). Control orientation and the illusion of control. Journal of Personality Assessment, 147, 369-374. 


\section{NOTES}

1. Because we did not use a directly competitive task, the factor is more appropriately described as modeling/social comparison factor. Competent and incompetent models were presented on videotape to introduce subjects to the task and to set a performance standard.

2. This was done for efficiency, rather than necessitated by theoretical or procedural issues.
3. Six subjects had BDI scores of at least 14 . For these subjects, the mean immediate prediction was 10.5 , thus failing to show an illusion of control. Their mean after-practice expectancy was 13.5. These means differed marginally $[t(5)=2.05, p<.10$, two-tailed], suggesting a tendency for even these moderately depressed subjects to exhibit an increasing illusion of control as a function of imagined practice.

(Manuscript received September 29, 1989.) 